\title{
A Bayesian model for predicting local El Niño events using tree ring widths and cellulose $\delta^{18} \mathrm{O}$
}

\author{
Jesse B. Nippert, ${ }^{1}$ Mevin B. Hooten, ${ }^{2}$ Darren R. Sandquist, ${ }^{3}$ and Joy K. Ward ${ }^{4}$
}

Received 24 July 2009; revised 6 October 2009; accepted 26 October 2009; published 16 March 2010.

[1] The oxygen stable isotopic composition $\left(\delta^{18} \mathrm{O}\right)$ of cellulose recorded in annual tree rings reflects the climate and precipitation history experienced during tree growth and development. Here, we show proxy evidence of El Niño events over the past 30 years using juniper tree rings from southern California, United States. The relationship between tree ring $\delta^{18} \mathrm{O}$ in $\alpha$ cellulose and annual ring width was negative during most years, reflecting amount-driven fractionation during precipitation. During El Niño years, the relationship between $\delta^{18} \mathrm{O}$ and ring width was positive with the largest ring widths correlated to the heaviest $\delta^{18} \mathrm{O}$. Warmer sea surface temperatures during vapor formation and the strengthening of vapor transport from the eastern Pacific Ocean inland is the most likely mechanism driving heavier $\delta^{18} \mathrm{O}$ in precipitation during El Niño years.

Based on this varying relationship between tree ring width and climate-dependent $\delta^{18} \mathrm{O}$ values, we created a model to estimate the probability that a given annual tree ring was formed during an El Niño or non-El Niño year. The methods used in this analysis differ from standard dendrochronological technique because we explicitly account for the varying relationship between climate and tree ring characteristic during an El Niño or non-El Niño year. Moreover, our approach accommodates uncertainty in model parameters and predictions better than traditional classification methods. The application of this model to prehistory tree samples or samples of unknown age may allow for El Niño detection and subsequent determination of changes in El Niño frequency.

Citation: Nippert, J. B., M. B. Hooten, D. R. Sandquist, and J. K. Ward (2010), A Bayesian model for predicting local El Niño events using tree ring widths and cellulose $\delta^{18} \mathrm{O}$, J. Geophys. Res., 115, G01011, doi:10.1029/2009JG001101.

\section{Introduction}

[2] At present, the El Niño-Southern Oscillation (ENSO) is the most significant source of climate variability in the world [Allan, 2000; Cane, 2005]. ENSO is a coupled instability between the ocean and atmosphere with direct effects localized to the tropical Pacific, while indirect telecommunications of ENSO extend to extratropical regions via altered global atmospheric circulation patterns [Hoerling and Kumar, 2000]. The ENSO system has a warm phase (El Niño) and a cool phase (La Niña). El Niño events have aperiodic occurrence every 2-7 years [Allan, 2000; Cane, 2005], but temporal variability ranges from seasonal (intraannual) to millennial timescales [Michaelsen, 1989; Mann et al., 2000; Tudhope et al., 2001]. During an El Niño event, alterations in sea surface temperature and pressure shift continental and oceanic climatic patterns, resulting in a

\footnotetext{
${ }^{1}$ Division of Biology, Kansas State University, Manhattan, Kansas, USA.

${ }^{2}$ Department of Mathematics and Statistics, Utah State University, Logan, Utah, USA.

${ }^{3}$ Department of Biological Science, California State University, Fullerton, California, USA.

${ }^{4}$ Department of Ecology and Evolutionary Biology, University of Kansas, Lawrence, Kansas, USA.

Copyright 2010 by the American Geophysical Union. 0148-0227/10/2009JG001101
}

deviation from the typical timing, amount, and distribution of precipitation [Allan et al., 1996; Allan, 2000]. These events contribute to increased precipitation variability, along with corresponding variability in terrestrial drought/flood patterns [Rind et al., 1990]. The likelihood that terrestrial vegetation in extratropical regions provides a record of El Niño periodicity is spatially specific, depending on local changes in climatic patterns and the degree to which local species respond and record changes in climate variability [e.g., Welker et al., 2005].

[3] The most consistent relationship between El Niño and precipitation in the United States has been observed for southern California [Schonher and Nicholson, 1989], although regionally specific extratropical El Niño responses in other regions of North America have been reported, but are less pronounced [Stahle et al., 1998; Cook et al., 2000]. For California, the relationship between El Niño events and precipitation variability is spatially and temporally specific [Schonher and Nicholson, 1989; Haston and Michaelsen, 1994]. The climate in this region is responsive to lowlatitude circulation changes, which can be directly linked to El Niño. The magnitude of El Niño effects varies between years of occurrence, but generally results in a wetter and warmer climate persisting into the winter months (DJF) [Schonher and Nicholson, 1989]. Southern California is generally water-limited, and thus annual fluctuations in precipitation (whether driven by El Niño or inherent climate 
variability) are likely to be recorded in tree growth patterns, and thus annual ring widths.

[4] Tree rings are commonly used to develop annual climate reconstructions, and these efforts tend to be most successful when one climate factor dominates tree growth and when the trees studied have grown on a well drained soil and rely predominantly on rainwater [Fritts, 1991; Schweingruber, 1996; Cook et al., 2000]. Dendroclimatic analyses have been used to link changes in tree ring growth to El Niño [Diaz et al., 2001], and to reconstruct ENSO indices including the Southern Oscillation Index [Michaelsen, 1989; Cleaveland et al., 1992; Meko, 1992; Stahle et al., 1998], Palmer Drought Severity Index [Treydte et al., 2007], and the Niño-3 sea surface temperature [Mann et al., 2000; D'Arrigo et al., 2005]. Some of the strongest proxy evidence recorded in tree rings for El Niño exists in conifers in the southwestern U.S. and northern Mexico [Michaelsen, 1989; Cleaveland et al., 1992; Stahle et al., 1998; Cook et al., 2000; Diaz et al., 2001; Leavitt et al., 2002]. At these arid and semiarid locations, El Niño-driven increases in winter precipitation amount increase soil moisture recharge and subsequently increase tree growth. The El Niño teleconnection is then recorded in variation in annual ring width that ultimately reflects changes in the amount of winter precipitation [Cook et al., 2000].

[5] Beyond the aforementioned physical growth proxies, the stable oxygen isotopic signature of cellulose in tree ring sequences also reveals climate conditions experienced throughout the lifespan of the tree [McCarroll and Loader, 2004; Loader et al., 2007]. The oxygen isotopic signature of tree ring cellulose contains information about environmental source water, relative humidity or leaf temperature during carbon fixation, as well as inherent plant physiological processes [Burk and Stuiver, 1981; Dawson and Ehleringer, 1993; Feng and Epstein, 1996; Roden et al., 2000; Anderson et al., 2002; Helle and Schleser, 2004; McCarroll and Loader, 2004; Etien et al., 2008; Helliker and Richter, 2008]. Differences in regional temperature and precipitation produce varying isotopic fractionation effects for $\delta^{18} \mathrm{O}$ of tree ring cellulose [Anderson et al., 2002; Treydte et al., 2007; Etien et al., 2008]. Because $\alpha$ cellulose $\delta^{18} \mathrm{O}$ does not contain exchangeable oxygen atoms, the signature does not fractionate over the life history of the tree [Roden et al., 2000, 2005], and provides a long-term record of the effects of environmental forcing on plant processes [Anderson et al., 2002; Evans and Schrag, 2004; Helle and Schleser, 2004; Roden et al., 2005; Mora et al., 2007].

[6] When changes in the oxygen isotopic signature are interpreted over a sequence, it provides information about the climate history [Vincent et al., 2007]. Climatic anomalies including El Niño [Evans and Schrag, 2004; Evans, 2007], and tropical cyclone activity [Miller et al., 2006; Mora et al., 2007] have been established using the isotopic signatures in individual tree rings. The nature of the proxy El Niño record using $\delta^{18} \mathrm{O}$ in tree rings has largely been regionally specific and the interpretation of tree ring $\delta^{18} \mathrm{O}$ variability is limited to the sample record used. In La Selva, Costa Rica, Evans [2007] reported a $\delta^{18} \mathrm{O}$ anomaly during El Niño years that, although not significant, appeared to correlate with changes in precipitation amount. In the work of Evans and Schrag [2004], no relationship between drought and El Niño for Costa Rica was found using $\delta^{18} \mathrm{O}$ in tree rings, but a strong single El Niño anomaly was detected in their Peru trees. Proxy El Niño records in these tree ring studies largely pertain to a single event, or events over a short timescale ( $<10$ years). El Niño sensitivity of climate is spatially variable, and in some places such as Belize, nodes exist with no discernable temperature or precipitation variations between ENSO cycles. These results provide proof of concept for regionally sensitive El Niño responses, and forecast the potential for using tree ring $\delta^{18} \mathrm{O}$ to reflect variability in precipitation patterns resulting from climate anomalies.

[7] This study aimed to identify a proxy for El Niño in tree ring data for southern California, United States. A tree ring proxy would have considerable value for predictive modeling of prehistory El Niño. Our objectives for this project were threefold, each based on the outcome of the proceeding objective: (1) to identify a record of El Niño events in juniper trees in southern California using the stable isotopic signature of tree ring cellulose, (2) to isolate a likely mechanism by which the stable isotopic signature of tree rings serves as an El Niño proxy, and (3) to propose a model using modern trees that may be applied to prehistory tree rings to differentiate El Niño versus non-El Niño years and that is easily extendable for more generalized modeling efforts (e.g., accommodation of covariates or autoregressive structure).

\section{Materials and Methods}

[8] We used California juniper (Juniperus californica Carrière) samples collected from an alluvial scrub community in the Lyttle Creek drainage near Fontana, California, Untied States $\left(34.14^{\circ} \mathrm{N}, 117.30^{\circ} \mathrm{W}\right)$. We collected a cross section of the bole at the base of three sample trees (minimum bole diameter: $15 \mathrm{~cm}$ ) located $0.2-0.3 \mathrm{~km}$ apart that were killed by the Grand Prix fire (21-23 October 2003). For the trees selected, the fire damaged the canopy, bark and vascular cambium, but not the secondary xylem. In 2003, these trees were 63, 75, and 98 years old. Despite the small sample size of this study, it is comparable to other isotopic studies characterizing a population response [Roden and Ehleringer, 2000; Leavitt et al., 2002; Evans and Schrag, 2004; McCarroll and Loader, 2004; Roden et al., 2005; Etien et al., 2008]. This is a low-elevation site (629 $\mathrm{m}$ asl) with a dry climate (mean annual precipitation: $389 \mathrm{~mm}$ ). The mean maximum and minimum temperatures for this site are 26.3 and $11.3^{\circ} \mathrm{C}$, respectively (climate data from the Western Regional Climate Center (WRCC) Fontana-Kaiser Station (043120)). The Fontana-Kaiser site was closed in 1984, and therefore climate data were used from the nearby $(52 \mathrm{~km})$ WRCC Riverside Fire Station 3 site (047470) for reconstruction of monthly temperature and precipitation patterns from 1970 to 2003 (Figure 1).

[9] Each wood sample was sanded and scanned on a flatbed scanner at high resolution (3000 dpi). Ring widths were then measured to the nearest $0.01 \mathrm{~mm}$. Anatomical structure can vary for a given year within a given tree based on varying environmental influences altering tension and compression zones within the bole [Schweingruber, 1996]. The radial distance from growth center (pith) to bark was not uniform along the circumference of each tree sample. To identify false rings as well as to determine mean annual ring 

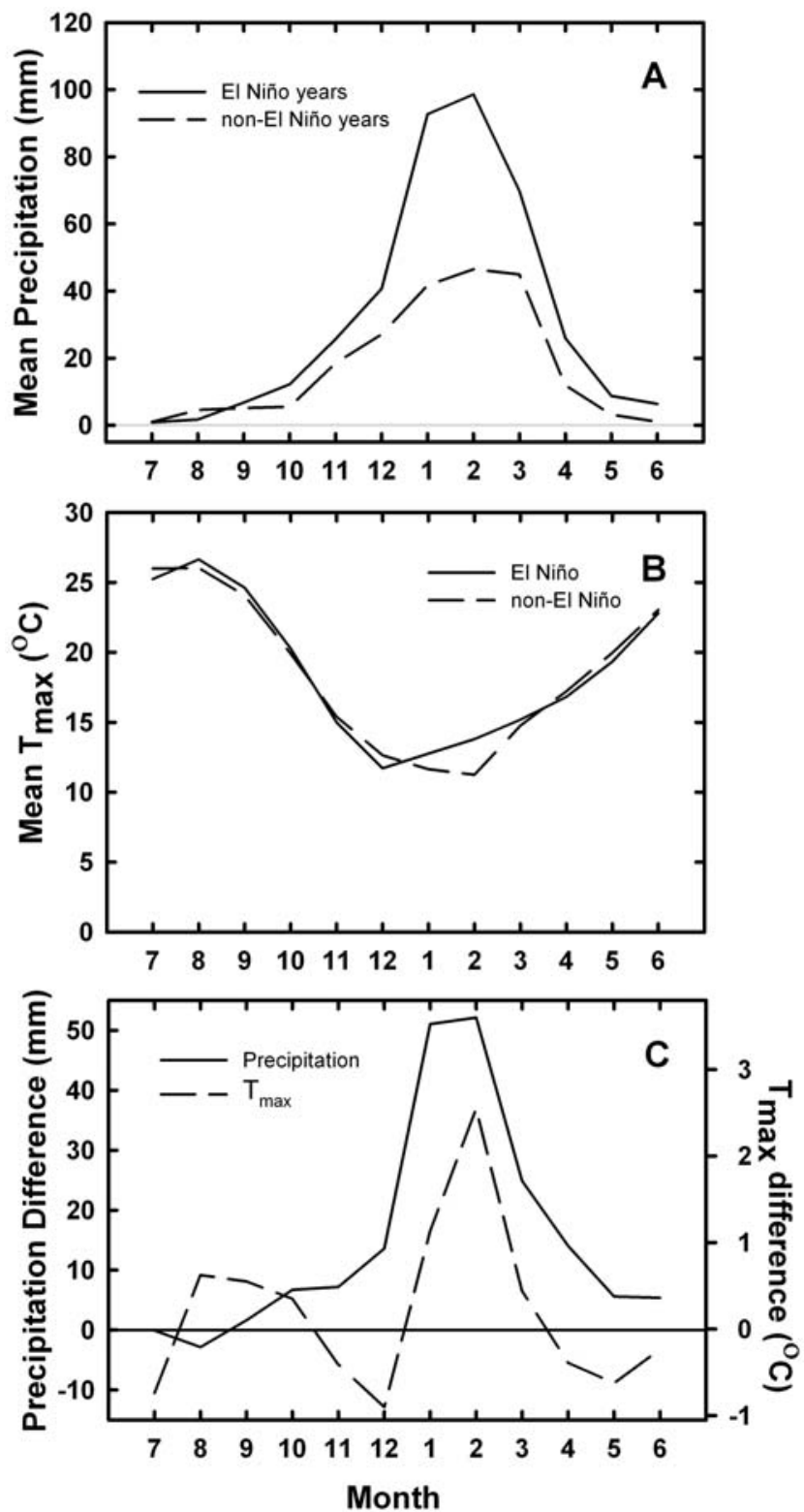

Figure 1. Mean monthly precipitation and maximum daily temperature $\left(\mathrm{T}_{\max }\right)$ from 1970 to 2003 from the WRCC Riverside Fire Station 3 climate station in southern California. ( $a$ and $b$ ) Solid lines are responses during El Niño years, while dashed lines are responses during non-El Niño years. (c) The mean monthly difference between El Niño and non-El Niño years for precipitation amount (left $y$ axis) and $\mathrm{T}_{\max }$ (right $y$ axis). Positive values indicate more precipitation or warmer temperatures comparatively during El Niño years.

widths for each tree sample, we traced individual rings around the circumference of the sample, and measured individual annual rings along five equally spaced radii drawn from pith to bark on each sample [see Vincent et al., 2007]. This technique helped to identify and eliminate false rings present in some but not all radii as well as eliminate biases associated with unequal ring widths for a given year depending on the location measured. Tree ring widths vary from nonclimate factors including variations in
(1) tree ring geometry, (2) age of tree, (3) tree history, (4) local stand conditions, and (5) site factors [Fritts, 1991]. To avoid age biases and temporal compression zones during tree growth, we analyzed only the sapwood portions of each sample, minimizing nonclimatic variations between heartwood and sapwood. Thus, our methodology accounted for these five sources of nonclimatic variation by measuring ring widths at multiple locations in the sample cross section, and focusing our analyses on samples from the same species, similar site, and similar ages, reducing variance associated with environmental history.

[10] Because individual rings were very narrow, it was not possible to separate early and late wood within a given year for stable isotopic analyses. However, $\delta^{18} \mathrm{O} \alpha$ cellulose was previously shown to not vary between early and late wood in Juniperus occidentalis from samples collected in central Oregon, United States [Roden et al., 2005]. We used a fine-tipped (1/64 in.) rotary drill on the stage of a dissecting microscope to collect wood samples from individual rings. For two of our samples, the sapwood began in 1980, while the third began in 1969. In this third sample, 8 rings were too small to generate sufficient sample for isotopic analysis. To accumulate a sufficient amount of sample for $\alpha$ cellulose extraction and subsequent stable isotopic analysis as well as to account for variation within a ring, many wood samples were collected within each ring and were aggregated within a tree (mean: 10 samples per ring per tree). Each tree sample cross section was cleaned thoroughly using compressed air between sampling of wood from individual rings to avoid contamination between years.

[11] We used the standard procedure to obtain $\alpha$ cellulose from individual tree rings [Leavitt and Danzer, 1993; Ward et al., 2005]. Stable isotopic analysis of $\alpha$ cellulose was performed using a TC/EA and Conflo III interface connected to a continuous-flow ThermoFinnigan Delta Plus-XP isotope ratio mass spectrometer (Bremen, Germany) at the Stable Isotope Core laboratory at Washington State University. Results are reported using standard delta notation:

$$
\delta=\left[\frac{R_{\text {sample }}}{R_{\text {standard }}}-1\right] \times 1000
$$

where $R_{\text {sample }}$ and $R_{\text {standard }}$ are the molar abundance ratios, ${ }^{18} \mathrm{O} /{ }^{16} \mathrm{O}$ of the sample and standard (Vienna standard mean ocean water), respectively. Data are expressed in per mil $(\%)$. IAEA-601 (true value is $23.30 \pm 0.3 \mathrm{SD}$ ) was used as an in-house quality control. The mean $( \pm 1 \mathrm{SD})$ value of IAEA-601 in our analysis was $23.31(0.15)$, and varied by $<0.15 \%$ across runs.

[12] Similar to Schongart et al. [2004], we defined El Niño years using the 3 month running means of SST anomalies that exceeded $0.4^{\circ} \mathrm{C}$ for 4 or more consecutive months. 'West Coast of Americas' SST records were obtained from the NOAA National Weather Service Climate Prediction Center (http://www.cpc.ncep.noaa.gov/data/indices/). We identified periods when the east Pacific SST anomaly persisted into the winter seasons, corresponding to Juniper growth in southern California. Based on this designation, we classified 9 periods between 1969 and 2003 as El Niño years for southwestern California that correspond temporally 
with the seasonal period of tree growth: 1973, 1977, 1983, 1987, 1988, 1992, 1993, 1995, and 1998.

[13] We created a mixture model to explicitly account for relationships between tree ring characteristics as well as the uncertainty in associated parameters and predictions. This model can be used to predict the likelihood of an El Niño year using measured values of tree ring width and $\delta^{18} \mathrm{O}$ of cellulose from juniper. This model uses an extendable framework for incorporating hierarchical model structure using a Bayesian approach for parameter estimation. Such a framework allows the user to easily upgrade the model to accommodate additional structure in future studies (e.g., spatial and/or temporal autocorrelation, covariates).

\subsection{Likelihood}

[14] We first let $x_{t}$ denote a vector of measurements (i.e., $\delta^{18} \mathrm{O}$ and tree ring width) at time $t$ and assume that it arises from one of two distributions, $f_{E}$ or $f_{N}$, depending on whether or not $t \in T_{E}$ (the set of El Niño years). This expression could also be written as $\mathbf{x}_{t} \mid y_{t} \sim f\left(y_{t}, \boldsymbol{\theta}\right)$, where $y_{t}$ is a random variable with binary support $\left(y_{t}=1\right.$ indicates time $t$ is an El Niño year), and $\boldsymbol{\theta}$ is a set of parameters contained in the distribution $f$. When $y_{t}$ is unknown, the following mixture model obtains:

$$
\mathbf{x}_{t} \sim\left\{\begin{array}{ll}
f_{\mathrm{E}}\left(\boldsymbol{\theta}_{\mathrm{E}}\right), \\
f_{N}\left(\boldsymbol{\theta}_{N}\right),
\end{array} \text { with probability } \begin{array}{l}
p_{\mathrm{t}}=P\left(y_{\mathrm{t}}=1\right) \\
1-p_{t}=P\left(y_{t}=0\right) .
\end{array}\right.
$$

Assuming that $\left\{\mathbf{x}_{t}, t \in T\right\}$ can be adequately modeled by a mixture of bivariate Gaussian distributions, and once $y_{t}$ has been observed, the likelihood equation follows:

$$
f\left(\mathbf{x}_{t} \mid \boldsymbol{\mu}_{E}, \boldsymbol{\Sigma}_{E}, \boldsymbol{\mu}_{N}, \boldsymbol{\Sigma}_{N}, y_{t}\right)=N\left(\boldsymbol{\mu}_{E}, \boldsymbol{\Sigma}_{E}\right)^{y t} \times \mathrm{N}\left(\boldsymbol{\mu}_{N}, \boldsymbol{\Sigma}_{N}\right)^{1-y_{t}}
$$

Statistical estimation of model parameters $\left(\boldsymbol{\mu}_{E}, \boldsymbol{\mu}_{N}, \boldsymbol{\Sigma}_{E}, \boldsymbol{\Sigma}_{N}\right.$, and $\left.\left\{p_{t}\right\}\right)$ can provide the necessary insight from which to make formal inference about the specific relationships between tree ring characteristics and El Niño. For example, the parameters $\boldsymbol{\mu}_{E}$ and $\boldsymbol{\mu}_{N}$, once estimated, will indicate average $\delta^{18} \mathrm{O}$ and ring width during $\mathrm{El}$ Niño and nonEl Niño years, respectively. Similarly, using the model specified, the two covariance matrices $\boldsymbol{\Sigma}_{E}$ and $\boldsymbol{\Sigma}_{N}$, once estimated, provide information about the specific relationship between $\delta^{18} \mathrm{O}$ and ring width. That is, the diagonal elements of $\boldsymbol{\Sigma}_{E}$ specify the variation in $\delta^{18} \mathrm{O}$ and ring width for each tree ring, whereas the off-diagonal elements specify the correlation between these characteristics during El Niño years (likewise for $\boldsymbol{\Sigma}_{N}$ during non-El Niño years). In this way, the model we have specified could be considered a Gaussian correlation model [e.g., Kutner et al., 2004]; the difference being that our data (i.e., $\delta^{18} \mathrm{O}$ and ring width expressed as $\mathbf{x}_{\mathrm{t}}$ ) can come from one of two Gaussian distributions depending on an El Niño or non-El Niño years. If the off-diagonal elements of $\boldsymbol{\Sigma}_{E}$ differ significantly from those of $\boldsymbol{\Sigma}_{N}$, this would imply that relationships between $\delta^{18} \mathrm{O}$ and ring width vary depending on whether the ring occurred in an El Niño or non-El Niño years. We utilized a Bayesian approach [Gelman et al., 2004] for statistical estimation in order to account for uncertainty in the parameters and provide an extendable framework for additional model structure. The statistical modeling approach presented here is largely phenomenological and developed specifically to exploit the empirically observed relationships between $\delta^{18} \mathrm{O}$ and ring width for this study region and species. While mechanistic models [e.g., Roden et al., 2000] have immense value for direct inference of the physiological mechanism responsible for the biological process using known environmental conditions, this approach allows for unsupervised inference and prediction allowing the data to guide the form of the relationships being modeled.

\subsection{Relation to Classification}

[15] Traditionally, the delineation of unknown observations into classification boundaries (observations of $\mathbf{x}_{t}$ into either El Niño or non-El Niño years) could be performed using Linear Discriminant Analysis (LDA) or Quadratic Discriminant Analysis [Mardia et al., 1979]. Advantages of these conventional methods revolve around their simplicity and nonparametric nature. They are especially useful for situations where classes are separable or even overlapping and specific distributional assumptions are hard to justify. However, we approached this problem in terms of prediction rather than classification. That is, we utilized new data, in terms of $\mathbf{x}_{t}$, for $t=t_{*}$, to predict whether year $t *$ was an El Niño year. Due to the fact that considerable uncertainty exists in any prediction of former climate, we characterized El Niño prediction in terms of probability of El Niño occurrence. Additionally, the Bayesian approach allowed us to characterize the variability in the predicted probability to aid in the construction of credible intervals (i.e., hypothesis tests, and possibly future modeling efforts). Thus, we considered $p_{t^{*}}=P\left(y_{t^{*}}=1\right)$ to be an unobserved random quantity about which we desired statistical inference.

\subsection{Parameters}

[16] Adopting a fully Bayesian approach in this context results in a very tractable parameter estimation framework as well as an intuitive method for El Niño prediction. The general Bayesian procedure requires the specification of a data model (i.e., the likelihood; specified in the previous section) and a set of parameter models. Here, we let the joint parameter model be factored into a sequence of independent probability models: $\left[\boldsymbol{\mu}_{E}, \boldsymbol{\mu}_{N}, \boldsymbol{\Sigma}_{E}, \boldsymbol{\Sigma}_{N},\left\{p_{t}\right\}\right]=$ $\left[\boldsymbol{\mu}_{E}\right]\left[\boldsymbol{\mu}_{N}\right]\left[\boldsymbol{\Sigma}_{E}\right]\left[\boldsymbol{\Sigma}_{N}\right]\left[\left\{p_{t}\right\}\right]$. Note that square bracket notation refers to a probability distribution and is commonly used in Bayesian literature [e.g., Cressie et al., 2009].

[17] More specifically, let $\boldsymbol{\mu}_{E} \sim N\left(\boldsymbol{\alpha}_{E}, \boldsymbol{\Sigma}_{\alpha, E}\right)$, and $\boldsymbol{\mu}_{N} \sim$ $N\left(\boldsymbol{\alpha}_{N}, \boldsymbol{\Sigma}_{\alpha, N}\right)$, where each bivariate Gaussian distribution was allowed to be vague a priori. The variance components are critical for accommodating the differing relationships in $\mathbf{x}_{t}$ under the varying climate regimes. To model each of the covariance structures, we used inverse Wishart random matrices, or equivalently: $\boldsymbol{\Sigma}_{E}^{-1} \sim \operatorname{Wish}\left(\left(\nu_{E} \mathbf{S}_{E}\right)^{-1}, \nu_{E}\right)$ and $\boldsymbol{\Sigma}_{N}{ }^{-1} \sim \operatorname{Wish}\left(\left(\nu_{N} \mathbf{S}_{N}\right)^{-1}, \nu_{N}\right)$, where the hyper-parameters are also selected to provide vague distributions a priori, but indicate the hypothesized difference in association (i.e., El Niño years indicate positively associated $\mathbf{x}_{t}$ while non-El Niño years indicate negatively associated $\mathbf{x}_{t}$ ). Thus, since the marginal expectation for the covariance matrices are of the form: $E(\boldsymbol{\Sigma})=\mathbf{S}, \mathbf{S}_{E}$ should have positive off-diagonals, while $\mathbf{S}_{N}$ should have negative off-diagonals. This latter spec- 


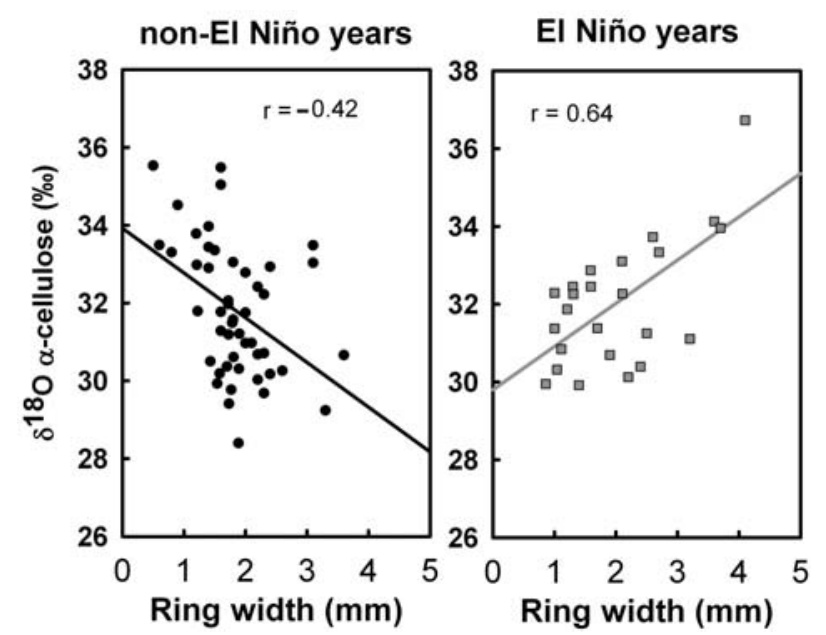

Figure 2. Changes in the stable isotopic signature of oxygen $\left(\delta^{18} \mathrm{O}\right)$ in $\alpha$ cellulose correlate with tree ring width during non-El Niño and El Niño years. Data reflect local environmental conditions recorded in juniper tree rings from 1969 to 2003 .

ification is reasonable, but likely unnecessary. The uniform distribution served as a reasonable prior model for the El Niño probabilities $\left(p_{\mathrm{t}}\right)$; we used it here to specify a lack of prior information which ensured that any information about El Niño came from the data.

\subsection{Implementation}

[18] Ultimately, we seek to predict, in the Bayesian context, the model parameters in the presence of data (i.e., $\mathbf{x}_{t}$ and $y_{t}$ for all $t$ ). This is accomplished by finding the posterior distribution of the model parameters given the data. In this case, the posterior distribution has the form:

$$
\begin{aligned}
& {\left[\boldsymbol{\mu}_{E}, \boldsymbol{\mu}_{N}, \boldsymbol{\Sigma}_{E}, \boldsymbol{\Sigma}_{N} \mid\left\{\mathbf{x}_{t}, \forall t\right\},\left\{y_{t}, \forall t\right\}\right] \alpha \prod_{t \in T}} \\
& \quad \cdot\left[\mathbf{x}_{t} \mid \boldsymbol{\mu}_{E}, \boldsymbol{\mu}_{N}, \boldsymbol{\Sigma}_{E}, \boldsymbol{\Sigma}_{N}, y_{t}\right]\left[\boldsymbol{\mu}_{E}\right]\left[\boldsymbol{\mu}_{N}\right]\left[\boldsymbol{\Sigma}_{E}\right]\left[\boldsymbol{\Sigma}_{N}\right]\left[\left\{p_{t}\right\}\right]
\end{aligned}
$$

A Markov Chain Monte Carlo algorithm can be constructed to sample from the posterior distribution by iteratively sampling from the much simpler full conditional distributions [Gamerman and Lopes, 2006]. The specific details of the algorithm are beyond the scope of this paper, but we refer the interested reader to McCarthy [2007] or Gelman et al. [2004] for more information on Bayesian methods and computation.

\subsection{Prediction}

[19] As previously mentioned, our goal was to utilize additional data regarding tree growth and physiology $\left(\mathbf{x}_{t=t^{*}}\right)$ to predict the probability of El Niño $\left(p_{t=t^{*}}=P\left(y_{t=t^{*}}=1\right)\right.$ for $t=t_{*}$ such that $y_{t=t^{*}}$ is unobserved). The probability that year $t_{*}$ was an El Niño year can be thought of as the probability that $\mathbf{x}_{t=t^{*}}$ arose from $f_{E}(\boldsymbol{\theta})$.

[20] In fact, since the parameters are considered to be random variables with probability distribution given by the posterior, the predicted probability of El Niño $\left(p_{t^{*}}\right)$ is random with its own distribution (i.e., the posterior predictive distribution). We can find this distribution (and thus use it for inference) given that we have tree ring data for the prediction year $t^{*}$ by integrating the joint posterior distribution over the remainder of the parameter space.

\section{Results}

[21] For Fontana, California, the majority of precipitation occurs between December and March, coinciding with the coolest daily maximum temperatures $\left(T_{\max }\right)$ (data for $1970-$ 2003; Figures 1a and 1b). Thus, half of the year is very dry (mean total precipitation May-October is $20.3 \mathrm{~mm}$; November-April is $190.5 \mathrm{~mm}$ ) and warm (mean MayOctober $\mathrm{T}_{\max }=23.2^{\circ} \mathrm{C}$ ). When considering El Niño years, however, there is a near doubling of winter precipitation (Figure 1a), with a corresponding increase in winter $T_{\max }$ (during January-March; Figures 1a-1c).

[22] Annual ring width was not significantly influenced $(p>0.05)$ by annual precipitation amount (water year JulyJune) for all tree ring samples combined (data not shown). When analyzed individually, growth in one tree was significantly related to water-year precipitation amount $(p<0.05$; $\mathrm{r}^{2}=0.20 ;$ intercept $=1.92 ;$ slope $\left.=0.06\right)$. The $\delta^{18} \mathrm{O}$ of $\alpha$ cellulose was not correlated to annual tree ring widths when compared across all sapwood years $(r=0.01)$. However, when the data were separated by climate history (nonEl Niño versus El Niño years), there was a negative correlation between $\delta^{18} \mathrm{O}$ and ring width during non-El Niño years $(r=-0.42)$, and a positive correlation during El Niño years $(r=0.64)$ (Figure 2).

[23] Utilizing the complete data set, we fit the mixture model previously discussed to estimate the relationships between ring width and $\delta^{18} \mathrm{O}$ within tree rings as well as to make predictions of El Niño probability on a grid of possible values using $\alpha$ cellulose $\delta^{18} \mathrm{O}$ and ring width (Figure 3a). The Bayesian approach allows for very rich statistical inference in which various forms of uncertainty are explicitly modeled. Specifically, fitting the model provides entire probability distributions for the predictions of El Niño (i.e., posterior predictive distributions). The resulting predictive distributions were then utilized to calculate the statistics necessary to facilitate inference (e.g., prediction standard deviation: Figure $3 b$ ). Using this information, we obtained hypothesis tests for significance by computing the quantity: $P\left(p_{*}>0.50\right)$. This result is interpreted as such: if the resulting quantity is above 0.95 , significant evidence of El Niño exists (black color in Figure 3c). Likewise, the quantity $P\left(p_{*}>0.50\right)$ can be used to test for non-El Niño years (white color in Figure 3c). Finally, all data points that do not fall significantly into one of the two regimes are labeled as inconclusive (gray color in Figure 3c).

[24] In order to perform a cross-validation we sequentially withheld each year of data for fitting the model and then predicted the probability of El Niño for each of those years. Figure 4 illustrates the predictive distribution for El Niño probability as a time series when considering all of the validation-based predictions together. From Figures 3 and 4 it is evident that the relationship between tree ring characteristics provides enough information to sufficiently detect El Niño and non-El Niño events during years when low 
and/or high probabilities are observed in the data (i.e., $\mathrm{x}_{t}$ ). However, when medium probability values were observed, the El Niño and non-El Niño signals become difficult to separate and thus predictions at those values are inconclu-

A

\section{El Niño Probability}

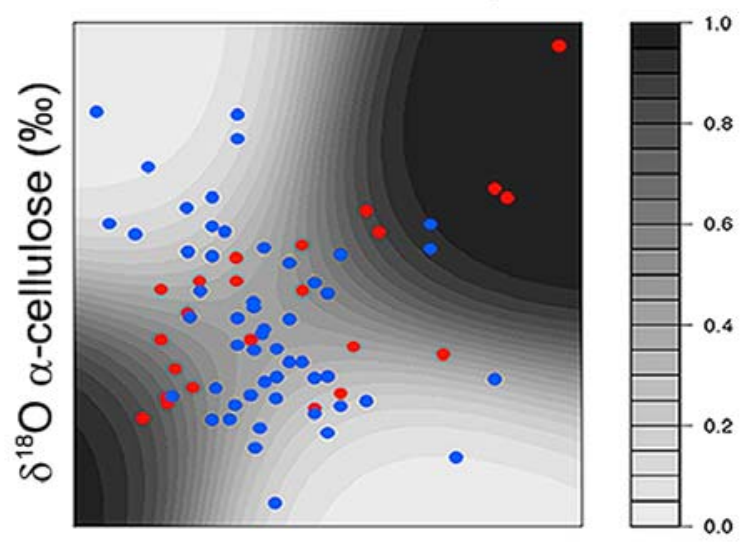

Ring-width ( $\mathrm{mm}$ )

B

El Niño Probability Std. Dev.

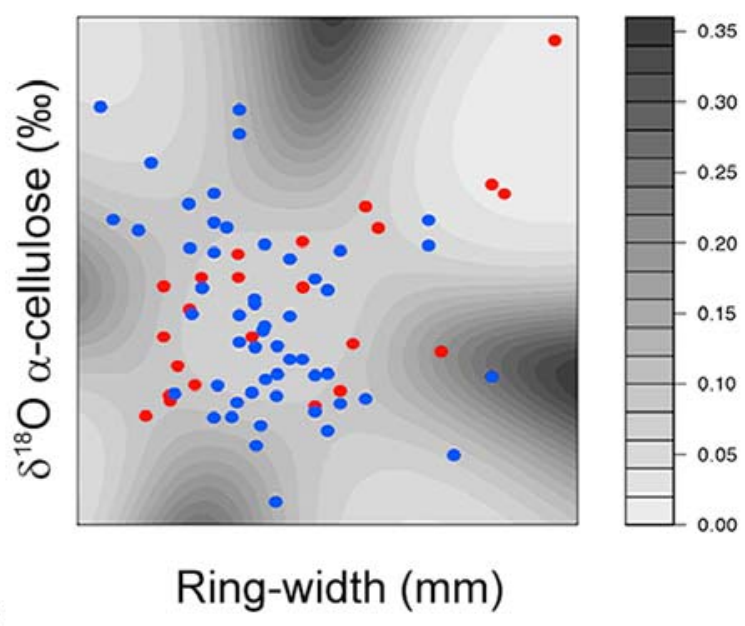

\section{El Niño Hypothesis Test}

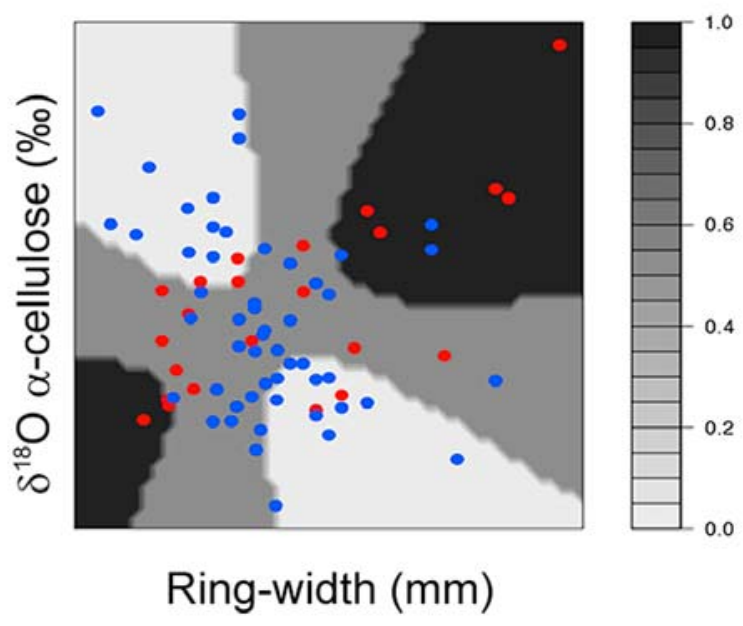

sive (i.e., gray areas in Figure $3 \mathrm{c}$ and dark shades near 0.50 in Figure 4).

\section{Discussion}

[25] The sign of the correlation between $\alpha$ cellulose $\delta^{18} \mathrm{O}$ and ring width in California juniper varied between El Niño and non-El Niño years, suggesting the predominant driver of isotopic fractionation varied during these periods, respectively. Tree ring $\delta^{18} \mathrm{O}$ varies according to changes in leaf evaporative enrichment that determines leaf water $\delta^{18} \mathrm{O}$, oxygen exchange between xylem water and the sugars used in cellulose synthesis, and variation in the oxygen isotopic signature of source water [Sternberg et al., 1986; Roden et al., 2000; Anderson et al., 2002; McCarroll and Loader, 2004; Barbour, 2007; Gessler et al., 2007]. In this study, the exchange of oxygen isotopes between xylem water and organic molecules are not a likely source of variability over time since we compared trees of the same species, similar age, and at the same location [Anderson et al., 2002]. The oxygen isotopic signature of leaf water reflects multiple environmental variables including relative humidity, $\delta^{18} \mathrm{O}$ of atmospheric vapor, and leaf vapor pressure deficit [Roden et al., 2000, 2005]. The effects of $\mathrm{CO}_{2}-\mathrm{H}_{2} \mathrm{O}$ equilibrium on leaf $\delta^{18} \mathrm{O}$ enrichment have been shown to be very small [Farquhar et al., 1998]. Similar to Roden et al. [2005], we assume the majority of growth in J. californica occurs in the winter to early spring, corresponding to the majority of annual rainfall and the coolest temperatures (Figure 1). During this period, cooler and more humid conditions would result in less evaporative enrichment of leaf water $\delta^{18} \mathrm{O}$ compared to drier and hotter periods of the year. Juniper is a shallow-rooted tree species with primary reliance on surface water $(<1 \mathrm{~m}$ deep) [Leffler et al., 2002; Eggemeyer et al., 2009], and therefore variability in precipitation would be expected to highly influence growth and physiology [Anderson et al., 2002; Helle and Schleser, 2004].

[26] Tree growth is limited by precipitation recharging surface water during El Niño and non-El Niño years (e.g., above-average rainfall contributed to above-average growth), yet changes in $\alpha$ cellulose $\delta^{18} \mathrm{O}$ reflected differences in precipitation $\delta^{18} \mathrm{O}$ which varied during El Niño events compared to non-El Niño periods. During a nonEl Niño year, the relationship between tree ring width and the $\delta^{18} \mathrm{O}$ of $\alpha$ cellulose was negative, indicative of an

Figure 3. Mixture model results fit to data from all tree ring samples. The data in each plot reflect individual tree ring widths and corresponding $\alpha$ cellulose $\delta^{18} \mathrm{O}$. Data from El Niño years are red, and data from non-El Niño years are blue. (a) Model predictions for the probability of El Niño and non-El Niño years are expressed as darker shading (El Niño year) and lighter shading (non-El Niño year). (b) Illustration of the uncertainty associated with the predicted probability in Figure 3a. Darker shading illustrates data regions of greater uncertainty. (c) Hypotheses tests for regions of significant $(P<0.05)$ El Niño probability (black shading) and non-El Niño probability (white shading) using estimates of uncertainty in Figure $3 \mathrm{~b}$. Gray regions are labeled as inconclusive $(P>0.05)$. 


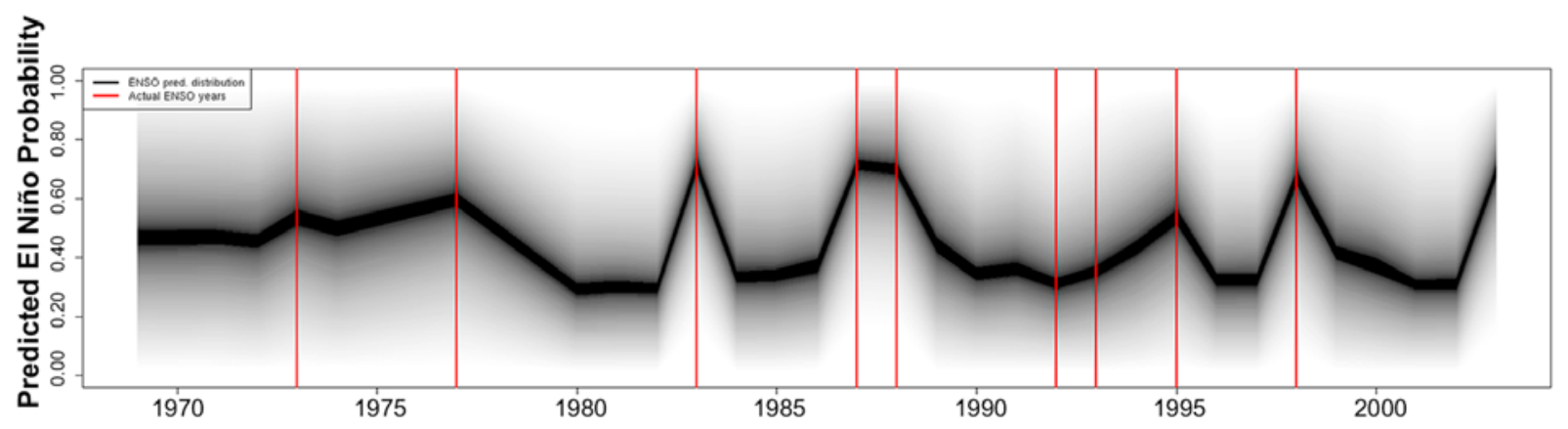

Figure 4. Cross-validation of the predictions of El Niño probability. Each year of data was sequentially withheld for model fitting, and then the probability of an El Niño year was predicted. Solid vertical lines illustrate actual El Niño years during this period. The black line represents the mode of the predictive distribution of El Niño probability over the years. The gray shading represents the predictive distribution itself, where darker gray indicates areas of high probability density (i.e., likely) and lighter values indicate lower-density areas (i.e., unlikely). Years where the gray shading is more spread out indicate a higher prediction variance (i.e., less certainty in the prediction).

amount-driven fractionation trend (Figure 2). This trend was likely reinforced by differences in evaporative soil and leaf enrichment occurring during wet and dry (non-El Niño) years. For example, during non-El Niño years, the negative relationship between $\delta^{18} \mathrm{O}$ and ring width indicated years with high rainfall and high rainout per storm produced lighter oxygen isotopic signatures [Gat, 1996] and wider tree rings (Figure 2). Conversely, smaller tree rings reflected a greater effect of low rainfall amounts and greater evaporative enrichment during dry, non-El Niño years [Gat, 1996]. A similar trend would occur from amount-driven fractionation resulting from secondary evaporation during rainfall [Dansgaard, 1964]. In this situation, smaller rainfall events are more enriched compared to larger events and would contribute to the negative relationship noted in Figure 2 during non-El Niño years.

[27] During El Niño years, the largest tree ring widths corresponded to the heaviest cellulose $\delta^{18} \mathrm{O}$ (Figure 2). This response likely reflects variability in zonal moisture transport and changes in sea surface temperature. During El Niño events, there is a substantial increase in moisture influx to the atmosphere from the northern and eastern Pacific and greater transport magnitudes of this vapor [Cohen et al., 2000; Sohn et al., 2004]. Trends in vapor transport reflect stronger lower tropospheric winds from strengthened Hadley circulation, and significantly enhanced Pacific ocean vapor flux during the winter in the northern hemisphere [Cohen et al., 2000]. Increases in the efficiency of vapor transport from the oceans to southern California would result in heavier precipitation because a greater fraction of heavy vapor arrives inland compared to large precipitation events during non-El Niño years. The larger ring widths and heavier $\delta^{18} \mathrm{O}$ during El Niño years also reflects the warmer winter air temperatures during these periods (late December to early March, Figures $1 b$ and 1c). Rainfall from water vapor formed at warmer temperatures is isotopically heavier than rainfall produced during cooler temperatures [Cole et al., 1993; Pendall, 2000; Evans and Schrag, 2004]. Therefore, the correspondence between large rings and heavier $\delta^{18} \mathrm{O}$ during El Niño years reflects SST anomalies forcing increased transport of water vapor formed under warmer Pacific SST.
[28] Using these varying patterns between non-El Niño and El Niño years we created a mixture model to identify the probability that a given tree ring was produced during a non-El Niño or El Niño year using the relationship between cellulose $\delta^{18} \mathrm{O}$ and ring width (Figure 3). This model has potential ecological and climatological value for identifying the history of El Niño events into prehistory periods. Furthermore, this framework accommodates various forms of uncertainty that would not be possible using traditional methods. For example, by allowing the parameters of the El Niño and non-El Niño distributions to be stochastic (i.e., variables in equations (2) and (3)) we allow for possible overdispersion in the model. This potential extra variability in the lower-level components will propagate through the model space to the predictions, preventing erroneous inference due to type I and II errors.

[29] Despite the influence of local environmental variability on ring widths and cellulose $\delta^{18} \mathrm{O}$ between non-El Niño and El Niño years, predictions of El Niño probability contain variability, especially in regions of overlap (Figure 3c, gray region). Uncertainty associated with predictions of El Niño probability would decrease with increased sample size, but some uncertainty will remain in regions where these relationships intersect. In fact, the model we developed (and any other model exploiting the described relationships between cellulose $\delta^{18} \mathrm{O}$ and ring width) will have inherent difficulty in predicting El Niño given data in the overlapping region. Thus, some misclassification is unavoidable (Figure 3c). Even with potential misclassification in overlapping regions, the approach we present is a significant improvement over traditional models because we are responsibly accounting for uncertainty in our predictions (Figure 4). Thus, the novelty of this technique is the emphasis placed on honestly accounting for uncertainty in the prediction to avoid drawing incorrect conclusions. It should be similarly noted that the predictive power of the model depends directly on the data used, and no other technique utilizing the relationship between cellulose $\delta^{18} \mathrm{O}$ and ring width would result in greater predictive power. For example, 1992 and 1993 are known to be El Niño years, but model prediction suggests they lean toward non-El Niño years (Figure 4). Data analyzed from these years occurred in 
the overlapping region. While these years were misclassified by the model, the corresponding variability is sufficiently high to recognize the low certainty in the El Niño prediction for those years. In contrast, predictions for years 1987 and 1988, which were El Niño years, provide significant evidence of El Niño due to both high probabilities and lower prediction variance. Thus, by including estimates of variability in the classification of data points to El Niño or non-El Niño periods, the inherent perils of misclassified data points are minimized.

[30] The analytical technique we used differs from traditional techniques using tree rings as a proxy of El Niño events. Generally, tree ring widths are standardized to remove low-order serial autocorrelation that may confound trends associated with biological rather than climatic persistence [Fritts, 1976]. However, when nonclimate growth trends are removed from tree rings, multidecadal El Niño variability is difficult to reconstruct using interannual variation in tree rings [Mann et al., 2000]. We did not standardize our ring widths using traditional techniques as this process would likely remove any El Niño signal, if present. Many traditional dendrochronological analyses employ some form of autoregressive modeling or spectral methods for examining periodic signals in tree ring data [Cook, 1992] that coincide with climatic traits (or their surrogates). The methods we have described and implemented are fundamentally different in their approach to the problem. The mixture model proposed in (2) was specifically formulated to allow for the estimation and exploitation of the relationships in tree ring characteristics to predict El Niño while explicitly accounting for variability in the data and uncertainty in the model parameters and predictions. Thus, this approach provides true statistical prediction and honest accounting of uncertainty in the solution. Moreover, post hoc analyses of periodicity via spectral methods can still be employed using the predictive distribution of El Niño probability itself.

\section{Conclusions}

[31] These results from juniper in southern California suggest that El Niño and non-El Niño years may be differentiated using changes in the relationship between ring width and $\alpha$ cellulose $\delta^{18} \mathrm{O}$. While these results are species-specific, similar trends may occur in other shallowrooted species with direct reliance on recent precipitation in this region. During El Niño events, increased vapor transport and warmer SST result in the delivery of precipitation to southern California with heavier $\delta^{18} \mathrm{O}$ corresponding to the largest ring widths. Predictive modeling of variability associated with El Niño may be possible for prehistory time periods for southern California, and perhaps for other regions with similar El Niño responses using the mixture model describing the uncertainty between $\delta^{18} \mathrm{O}$ in tree ring cellulose and the corresponding ring widths. Our ability to link modern $\delta^{18} \mathrm{O}$-growth response in tree rings as a predictor of El Niño years is contingent upon a similar El Niño response for this region over the recent millennia. If El Niño-driven changes in past climate variability are similar to the present, then changes in $\delta^{18} \mathrm{O}$ recorded in $\alpha$ cellulose may be useful for estimates of climate-biotic relationships beyond periods of recorded history [Anderson et al., 2002; Leavitt et al., 2002; Loader et al., 2007].

[32] Acknowledgments. We thank Scott Spal and Ben Harlow for analytical support and Adele Cutler for statistical advice and suggestions. Brent Helliker, Gabe Bowen, Lucas Cernusak, Dork Sahagian, and anonymous reviewers provided valuable comments that improved this manuscript. This research was supported by NSF-0517668 and 0746822 .

\section{References}

Allan, R. J. (2000), ENSO and climatic variability in the past 150 years, in El Nino and the Southern Oscillation: Multiscale Variability and Global and Regional Impacts, edited by S. C. Diaz and V. Markgraf, pp. 3-55, Cambridge Univ. Press, Cambridge, U. K.

Allan, R. J., J. A. Lindesay, and D. E. Parker (1996), El Nino Southern Oscillation and Climatic Variability, CSIRO, Melbourne.

Anderson, W. T., S. M. Bernasconi, J. A. McKenzie, M. Saurer, and F. Schweingruber (2002), Model evaluation for reconstructing the oxygen isotopic composition in precipitation from tree ring cellulose over the last century, Chem. Geol., 182, 121-137, doi:10.1016/S0009-2541(01) 00285-6.

Barbour, M. M. (2007), Stable oxygen isotope composition of plant tissue: A review, Funct. Plant Biol., 34, 83-94, doi:10.1071/FP06228.

Burk, R. L., and M. Stuiver (1981), Oxygen isotope ratios in trees reflect mean annual temperature and humidity, Science, 211, 1417-1419, doi:10.1126/science.211.4489.1417

Cane, M. A. (2005), The evolution of El Nino, past and future, Earth Planet. Sci. Lett., 230, 227-240, doi:10.1016/j.epsl.2004.12.003.

Cleaveland, M. K., E. R. Cook, and D. W. Stahle (1992), Secular variability of the Southern Oscillation detected in tree-ring data from Mexico and the southern United States, in El Nino: Historical and Paleoclimate Aspects of the Southern Oscillation, edited by S. C. Diaz and V. Markgraf, pp. 271-291, Cambridge Univ. Press, Cambridge, U. K.

Cohen, J. L., D. A. Salstein, and R. D. Rosen (2000), Interannual variability in the meridional transport of water vapor, J. Hydrometeorol., 1 , 547-553, doi:10.1175/1525-7541(2000)001<0547:IVITMT>2.0.CO;2.

Cole, J. E., R. G. Fairbanks, and G. T. Shen (1993), Recent variability in the Southern Oscillation: Isotopic results from a Tarawa Atoll coral, Science, 260, 1790-1793, doi:10.1126/science.260.5115.1790.

Cook, E. R. (1992), Using tree rings to study past El Nino/Southern Oscillation influences on climate, in El Nino: Historical and Paleoclimatic Aspects of the Southern Oscillation, edited by H. F. Diaz and V. Markgraf, pp. 203-214, Cambridge Univ. Press, Cambridge, U. K.

Cook, E. R., R. D. D’Arrigo, J. E. Cole, D. W. Stahle, and R. Villalba (2000), Tree-ring records of past ENSO variability and forcing, in El Nino and the Southern Oscillation: Multiscale Variability and Global and Regional Impacts, edited by S. C. Diaz and V. Markgraf, pp. 297-323, Cambridge Univ. Press, Cambridge, U. K.

Cressie, N. A. C., C. A. Calder, J. S. Clark, J. M. Ver Hoef, and C. K. Wikle (2009), Accounting for uncertainty in ecological analysis: The strengths and limitations of hierarchical statistical modeling, Ecol. Appl., 19, 553-570, doi:10.1890/07-0744.1.

Dansgaard, W. (1964), Stable isotopes in precipitation, Tellus, 16, $436-468$.

D’Arrigo, R., E. R. Cook, R. J. Wilson, R. Allan, and M. E. Mann (2005), On the variability of ENSO over the past six centuries, Geophys. Res. Lett., 32, L03711, doi:10.1029/2004GL022055.

Dawson, T. E., and J. R. Ehleringer (1993), Isotopic enrichment of water in the woody tissues of plants - implications for plant water source, wateruptake, and other studies which use the stable isotopic composition of cellulose, Geochim. Cosmochim. Acta, 57, 3487-3492, doi:10.1016/ 0016-7037(93)90554-A

Diaz, S. C., R. Touchan, and T. W. Swetnam (2001), A tree-ring reconstruction of past precipitation for Baja California Sur, Mexico, Int. J. Climatol., 21, 1007-1019, doi:10.1002/joc.664.

Eggemeyer, K. D., T. Awada, F. E. Harvey, D. A. Wedin, X. Zhou, and C. W. Zanner (2009), Seasonal changes in the depth of water uptake for encroaching trees Juniperus virginiana and Pinus ponderosa and two dominant $\mathrm{C}_{4}$ grasses in a semiarid grassland, Tree Physiol., 29, $157-$ 169, doi:10.1093/treephys/tpn019.

Etien, N., V. Daux, V. Masson-Delmotte, O. Mestre, M. Stievenard, M.-T. Guillemin, T. Boettger, N. Breda, M. Haupt, and P. P. Perraud (2008), Summer maximum temperature in northern France over the past century: Instrumental data versus multiple proxies (tree-ring isotopes, grape harvest dates and forest fires), Clim. Change, doi:10.1007/ s10584-008-9516-8 
Evans, M. N. (2007), Toward forward modeling for paleoclimatic proxy signal calibration: A case study with oxygen isotopic composition of tropical woods, Geochem. Geophys. Geosyst., 8, Q07008, doi:10.1029/ 2006GC001406.

Evans, M. N., and D. P. Schrag (2004), A stable isotope-based approach to tropical dendroclimatology, Geochim. Cosmochim. Acta, 68, 3295-3305, doi:10.1016/j.gca.2004.01.006.

Farquhar, G. D., M. M. Barbour, and B. K. Henry (1998), Interpretation of oxygen isotope composition of leaf material, in Stable Isotopes. Integration of Biological, Ecological, and Geochemical Processes, edited by H. Griffiths, BIOS Sci., Oxford, U. K.

Feng, X. H., and S. Epstein (1996), Climatic trends from isotopic records of tree rings: The past 100-200 years, Clim. Change, 33, 551-562, doi:10.1007/BF00141704.

Fritts, H. C. (1976), Tree Rings and Climate, Academic, London.

Fritts, H. C. (1991), Reconstructing Large-Scale Climatic Patterns From Tree-Ring Data: A Diagnostic Analysis, Univ. of Ariz. Press, Tucson.

Gamerman, D., and H. F. Lopes (2006), Markov Chain Monte Carlo, Stochastic Simulation for Bayesian Inference, Chapman and Hall, New York.

Gat, J. R. (1996), Oxygen and hydrogen isotopes in the hydrologic cycle, Annu. Rev. Earth Planet. Sci., 24, 225-262, doi:10.1146/annurev. earth.24.1.225

Gelman, A., J. B. Carlin, H. S. Stern, and D. B. Rubin (2004), Bayesian Data Analysis, Chapman and Hall, New York.

Gessler, A., A. D. Peuke, C. Keitel, and G. D. Farquhar (2007), Oxygen isotope enrichments of organic matter in Ricinus communis during the dial course and as affected by assimilate transport, New Phytol., 174 , 600-613, doi:10.1111/j.1469-8137.2007.02007.x.

Haston, L., and J. Michaelsen (1994), Long-term central coastal California precipitation variability and relationships to El-Nino-Southern Oscillation, J. Clim., 7, 1373-1387, doi:10.1175/1520-0442(1994)007<1373: $\mathrm{LTCCCP}>2.0 . \mathrm{CO} ; 2$

Helle, G., and G. H. Schleser (2004), Interpreting climate proxies from treerings, in The KIHZ Project: Towards a Synthesis of Holocene Proxy Data and Climate Models, edited by H. Fischer et al., pp. 129-148, Springer, Berlin.

Helliker, B. R., and S. L. Richter (2008), Subtropical to boreal convergence of tree-leaf temperatures, Nature, 454, 511-514, doi:10.1038/ nature 07031

Hoerling, M. P., and A. Kumar (2000), Understanding and predicting extratropical teleconnections related to El Niño, in El Nino and the Southern Oscillation: Multiscale Variability and Global and Regional Impacts edited by H. F. Diaz and V. Markgraf, pp. 57-88, Cambridge Univ. Press, Cambridge, U. K.

Kutner, M. H., C. J. Nachtsheim, and J. Neter (2004), Applied Linear Regression Models, McGraw-Hill, New York

Leavitt, S. W., and S. R. Danzer (1993), Method for batch processing small wood samples to holocellulose for stable-carbon isotope analysis, Anal. Chem., 65, 87-89, doi:10.1021/ac00049a017.

Leavitt, S. W., W. E. Wright, and A. Long (2002), Spatial expression of ENSO, drought, and summer monsoon in seasonal delta C-13 of ponderosa pine tree rings in southern Arizona and New Mexico, J. Geophys. Res., 107(D18), 4349, doi:10.1029/2001JD001312.

Leffler, A. J., R. J. Ryel, L. Hipps, S. Ivans, and M. M. Caldwell (2002), Carbon acquisition and water use in a northern Utah Juniperus osteosperma (Utah juniper) population, Tree Physiol., 22, 1221-1230.

Loader, N. J., D. McCarroll, M. Gagen, I. Robertson, and R. Jalkanen (2007), Extracting climatic information from stable isotopes in tree rings, in Stable Isotopes as Indicators of Ecological Change, edited by T. E. Dawson and R. Siegwolf, pp. 27-48, Academic, Amsterdam, Netherlands

Mann, M. E., R. S. Bradley, and M. K. Hughes (2000), Long-term variability in the El Nino/Southern Oscillation and associated teleconnections, in El Nino and the Southern Oscillation: Multiscale Variability and Global and Regional Impacts, edited by H. F. Diaz and V. Markgraf, pp. $357-$ 412, Cambridge Univ. Press, Cambridge, U. K.

Mardia, K. V., J. T. Kent, and J. M. Bibby (1979), Multivariate Analysis, Academic, San Diego, Calif.

McCarroll, D., and N. J. Loader (2004), Stable isotopes in tree rings, Quat. Sci. Rev., 23, 771-801, doi:10.1016/j.quascirev.2003.06.017.

McCarthy, M. A. (2007), Bayesian Methods for Ecology, Cambridge Univ. Press, Cambridge, U. K.

Meko, D. M. (1992), Special properties of tree-ring data in the United States Southwest as related to El Nino/Southern Oscillation, in Historical and Paleoclimatic Aspects of the Southern Oscillation, edited by H. F. Diaz and V. Markgraf, pp. 227-241, Cambridge Univ. Press, Cambridge, U. K.

Michaelsen, J. (1989), Long-period fluctuations in El Nino amplitude and frequency reconstructed from tree-rings, in Aspects of Climate Variability in the Pacific and the Western Americas, Geophys. Monogr. Ser., vol. 55, edited by D. H. Peterson, pp. 69-74, AGU, Washington, D. C.

Miller, D. L., C. I. Mora, H. D. Grissino-Mayer, C. J. Mock, M. E. Uhle, and Z. Sharp (2006), Tree-ring isotope records of tropical cyclone activity, Proc. Natl. Acad. Sci. U. S. A., 103, 14,294-14,297, doi:10.1073/ pnas.0606549103

Mora, C. I., D. L. Miller, and H. D. Grissino-Mayer (2007), Oxygen isotope proxies in tree-ring cellulose: Tropical cyclones, drought, and climate oscillations, in Stable Isotopes as Indicators of Ecological Change, edited by T. E. Dawson and R. Siegwolf, pp. 63-76, Academic, Amsterdam, Netherlands.

Pendall, E. (2000), Influence of precipitation seasonality on pinon pine cellulose delta D values, Global Change Biol., 6, 287-301, doi:10.1046/j.1365-2486.2000.00304.x.

Rind, D., R. Goldberg, J. Hansen, C. Rosenzweig, and R. Ruedy (1990), Potential evapotranspiration and the likelihood of future drought J. Geophys. Res., 95(D7), 9983-10,004, doi:10.1029/JD095iD07p09983.

Roden, J. S., and J. R. Ehleringer (2000), Hydrogen and oxygen isotope ratios of tree ring cellulose for field-grown riparian trees, Oecologia, 123 481-489, doi:10.1007/s004420000349

Roden, J. S., G. G. Lin, and J. R. Ehleringer (2000), A mechanistic model for interpretation of hydrogen and oxygen isotope ratios in tree-ring cellulose, Geochim. Cosmochim. Acta, 64, 21-35, doi:10.1016/S00167037(99)00195-7.

Roden, J. S., D. R. Bowling, N. G. McDowell, B. J. Bond, and J. R. Ehleringer (2005), Carbon and oxygen isotope ratios of tree ring cellulose along a precipitation transect in Oregon, United States, J. Geophys. Res., 110, G02003, doi:10.1029/2005JG000033.

Schongart, J., W. J. Junk, M. T. F. Piedade, J. M. Ayres, A. Huttermann, and M. Worbes (2004), Teleconnection between tree growth in the Amazonian floodplains and the El Nino-Southern Oscillation effect, Global Change Biol., 10, 683-692, doi:10.1111/j.1529-8817.2003.00754.x.

Schonher, T., and S. E. Nicholson (1989), The relationship between California rainfall and El Niño events, J. Clim., 2, 1258-1269, doi:10.1175/1520-0442(1989)002<1258:TRBCRA>2.0.CO;2.

Schweingruber, F. H. (1996), Tree rings and environment dendroecology, Birmensdorf, Swiss Fed. Inst. for For., Snow and Landscape Res., Bern. Sohn, B.-J., E. A. Smith, F. R. Robertson, and S.-C. Park (2004), Derived over-ocean water vapor transports from satellite-retrieved $\mathrm{E}-\mathrm{P}$ datasets, J. Clim., 17, 1352-1364, doi:10.1175/1520-0442(2004)017<1352: DOWVTF $>2.0 . \mathrm{CO} ; 2$

Stahle, D. W., et al. (1998), Experimental dendroclimatic reconstruction of the Southern Oscillation, Bull. Am. Meteorol. Soc., 79, 2137-2152, doi:10.1175/1520-0477(1998)079<2137:EDROTS >2.0.CO;2

Sternberg, L., M. De Niro, and R. Savidge (1986), Oxygen isotope exchange between metabolites and water during biochemical reactions leading to cellulose synthesis, Plant Physiol., 82, 423-427, doi:10.1104/pp.82. 2.423 .

Treydte, K., et al. (2007), Signal strength and climate calibration of a European tree-ring isotope network, Geophys. Res. Lett., 34, L24302, doi:10.1029/2007GL031106.

Tudhope, A. W., C. P. Chilcott, M. T. McCulloch, E. R. Cook, J. Chappell, R. M. Ellam, D. W. Lea, J. M. Lough, and G. B. Shimmield (2001) Variability in the El Nino-Southern Oscillation through a glacial-interglacial cycle, Science, 291, 1511-1517, doi:10.1126/science.1057969.

Vincent, L., G. Pierre, S. Michel, N. Robert, and V. Masson-Delmotte (2007), Tree-rings and the climate of New Caledonia (SW Pacific) preliminary results from Araucariacae, Palaeogeogr. Palaeoclimatol. Palaeoecol., 253, 477-489, doi:10.1016/j.palaeo.2007.06.019.

Ward, J. K., J. M. Harris, T. E. Cerling, A. Wiedenhoeft, M. J. Lott, M. D. Dearing, J. B. Coltrain, and J. R. Ehleringer (2005), Carbon starvation in glacial trees recovered from the La Brea tar pits, southern California, Proc. Natl. Acad. Sci. U. S. A., 102, 690-694, doi:10.1073/ pnas.0408315102.

Welker, J. M., S. Rayback, and G. H. R. Henry (2005), Arctic and North Atlantic Oscillation phase changes are recorded in the isotopes (delta O-18 and delta C-13) of Cassiope tetragona plants, Global Change Biol., 11, 997-1002, doi:10.1111/j.1365-2486.2005.00961.x.

M. B. Hooten, Department of Mathematics and Statistics, Utah State University, Logan, UT 84322, USA.

J. B. Nippert, Division of Biology, Kansas State University, Manhattan, KS 66506, USA. (nippert@ksu.edu)

D. R. Sandquist, Department of Biological Science, California State University, Fullerton, CA 92834, USA

J. K. Ward, Department of Ecology and Evolutionary Biology, University of Kansas, Lawrence, KS 66045, USA 